\title{
Factors Predicting Mortality in Perforation Peritonitis at a Tertiary Care Center in Nepal
}

\author{
Prasan Kansakar', Bikal Ghimire'1, Parashuram Mishra² \\ 'Department of Gl and General Surgery, Maharajgunj Medical Campus, Tribhuvan University Teaching Hospital, Institute \\ of Medicine, Maharajgunj, Kathmandu, Nepal, ${ }^{2}$ Department of Surgery, Gandaki Medical College Teaching Hospital, \\ Prithvi Chowk, Pokhara, Nepal
}

\section{Corresponding author:}

Prasan Kansakar, MS, MCh

Department of Gl and General Surgery, Maharajgunj Medical Campus, Tribhuvan University Teaching Hospital, Institute of Medicine, Maharajgunj, Kathmandu, Nepal

Email:pbskansakar@hotmail.com

Submitted : October 16, 2019

Accepted : December 1, 2019

\begin{abstract}
Introduction

Perforation peritonitis is a common surgical emergency. Despite advances in surgical techniques, antimicrobial therapy and intensive care support, mortality due to this illness still remains high. To analyze various demographic and clinical parameters associated with mortality in patients undergoing surgery for hollow viscus perforation peritonitis.
\end{abstract}

\section{Methods}

A prospective observational study was conducted at the Surgical Gastroenterology Unit, Department of Surgery, Tribhuvan University Teaching Hospital, in patients undergoing surgery for perforation peritonitis over a period of 18 months. Demographic characteristics, physiological variables and laboratory values were obtained. End point of the study was patients' condition at discharge or in-hospital mortality. Univariate and multivariate analysis of various demographic, clinical and laboratory parameters were performed.

\section{Results}

Among 121 patients, mean age was $41.5 \pm 18.9$ years (range of 16 to 87 years). There was a male preponderance (74.1\%). In-hospital mortality was seen in 19 patients (17.0\%). Age, female sex, pulse rate, blood pressure, white blood cell count, urea and creatinine were significant parameters associated with mortality. Multivariate logistic regression analysis of the variables found to be of significance from univariate analysis showed that only pulse, systolic blood pressure and creatinine were the independent variables associated with mortality.

\section{Conclusion}

Higher mortality was seen in elderly patients. Despite of male preponderance, larger proportion of females succumbed to their disease. Derrangement in vital parameters like pulse and blood pressure and renal function test had negative impact in survival.

Keywords: Hollow viscus, mortality, perforation peritonitis

\section{INTRODUCTION}

$\mathrm{M}$ ortality associated with perforation peritonitis remains relatively high. ${ }^{1}$ It is difficult to predict mortality at the time of presentation. However, there are certain demographic, clinical and laboratory parameters regarded as high risk. Presence of these high risk factors may guide clinicians to be more watchful in such subset of patients. ${ }^{2}$ Objective of this study was to identify various demographic, clinical and laboratory parameters associated with mortality in patients undergoing surgery for perforation peritonitis. 
Table 1. Demographic and clinical parameters for survivors and non survivors

\begin{tabular}{lcccc}
\hline \multicolumn{1}{c}{ Parameters } & $\begin{array}{c}\text { Total } \\
\mathrm{n}=112\end{array}$ & $\begin{array}{c}\text { Survivors } \\
\mathrm{n}=93\end{array}$ & $\begin{array}{c}\text { Non survivors } \\
\mathrm{n}=19\end{array}$ & $\mathrm{p}$-value \\
\hline Age & $41.5 \pm 18.9$ & $39.2 \pm 18.7$ & $53.2 \pm 15.8$ & 0.003 \\
Male & 83 & $73(88.0)$ & $10(12.0 \%)$ & 0.019 \\
Female & 29 & $20(69.0)$ & $9(31.0 \%)$ & 0.241 \\
Median duration of & & & & $<.0$ \\
symptoms (days) & 2.0 & 2.0 & $119.6 \pm 24.9$ & $<0.001$ \\
Pulse & $104.1 \pm 21.3$ & $100.9 \pm 19.2$ & $90.7 \pm 16.8$ & $<0.001$ \\
Systolic BP & $112.0 \pm 21.6$ & $116.3 \pm 19.9$ & & \\
\end{tabular}

\section{METHODS}

A prospective observational study was conducted at the Surgical Gastroenterology Units of Department of Surgery, Tribhuvan University Teaching Hospital, Kathmandu, Nepal, over a period of 18 months (July 1, 2011 to November 30, 2012). Ethical approval was obtained from the Institutional Review Board of Institute of Medicine. Informed consent was taken from all the patients before enrolling them into the study. All patients undergoing surgery for suspected perforation peritonitis were included in the study. Patients aged less than 16 years, discharged on request and patients in whom no perforation found during surgery were excluded from the study. Statistical analysis performed with SPSS 16.0 (SPSS, Chicago, III). Results expressed as mean \pm standard deviation. T-test to compare difference between two groups. All statistical tests with $\mathrm{P}<0.05$ considered statistically significant.

\section{RESULTS}

A total of 121 patients underwent surgery for perforation peritonitis during the study period. Mean age of the patients was $41.5 \pm 18.9$ years with range of $16-87$ years. There was a male preponderance with male to female ratio of $2.9: 1$. 19 patients $(17.0 \%)$ of the patient died.

Comparison of demographic and clinical parameters between survivors and non survivors are depicted in Table 1. Non-survivors were significantly older in comparison to survivors. $(53.2 \pm 15.8$ versus 39.2 \pm 18.7 years). Though male patients outnumbered female patients, there were a larger proportion of females among non survivors. However, on analyzing other confounding factors such as age ( $p$ $=0.295)$ and duration of symptoms $(p=0.364)$, the difference in survival was not significant. Similarly, the median duration of symptoms likewise did not vary statistically ( $p=0.241$ ) Pulse rate in non survivors was $100.9 \pm 19.2$ as compared to 119.6 \pm 24.9 in non survivors $(p<0.001)$. Systolic blood pressure in survivors and non- survivors was 116.3 $\pm 19.9 \mathrm{mmHg}$ and $90.7 \pm 16.8 \mathrm{mmHg}$ respectively $(p<0.001)$. Hence, variation in vital parameters, such as pulse and systolic blood pressure was found to be significantly different between survivors and non survivors.

Comparison of laboratory parameters between survivors and non survivors is given in Table 2 . Levels of hemoglobin, sodium and potassium were not found to be significantly different between survivors and non- survivors. White blood cell count was lower in the non- survivors $(p=0.048)$. Levels of urea and creatinine were significantly elevated in the non survivors.

Non traumatic bowel perforation accounted for $63.4 \%$ of all patients. Mode of bowel perforation, whether non traumatic, penetrating or blunt injuries were not found to be associated with increased mortality $(p=0.068)$. Duodenum was the commonest site of perforation which accounted

Table 2. Laboratory parameters in survivors and non survivors

\begin{tabular}{lcccc}
\hline \multicolumn{1}{c}{ Parameters } & $\begin{array}{c}\text { Total } \\
\mathrm{n}=112\end{array}$ & $\begin{array}{c}\text { Survivors } \\
\mathrm{n}=93\end{array}$ & $\begin{array}{c}\text { Non survivors } \\
\mathrm{n}=19\end{array}$ & $\mathrm{p}$-value \\
\hline Hemoglobin $(\mathrm{g} / \mathrm{L})$ & $13.4 \pm 2.7$ & $13.6 \pm 2.4$ & $12.1 \pm 3.6$ & 0.26 \\
WBC count $(/ \mathrm{cmm})$ & $9422.3 \pm 5394$ & $9876.1 \pm 5308.1$ & $7201.1 \pm 5400.0$ & 0.048 \\
Urea $(\mathrm{mmol} / \mathrm{L})$ & $8.1 \pm 6.2$ & $7.0 \pm 4.3$ & $13.8 \pm 10.2$ & $<0.001$ \\
Creatinine $(\mu \mathrm{mol} / \mathrm{L}))$ & $121.1 \pm 68.3$ & $108.4 \pm 51.3$ & $182.3 \pm 102.0$ & $<0.001$ \\
Sodium $(\mathrm{mmol} / \mathrm{L})$ & $137.75 \pm 6.5$ & $138.0 \pm 6.5$ & $136.7 \pm 6.4$ & 0.43 \\
Potassium(mmol/L) & $4.1 \pm 0.7$ & $4.1 \pm 0.6$ & $4.3 \pm 1.0$ & 0.311 \\
\hline
\end{tabular}


Table 3. Site of perforation in survivors and non survivors

\begin{tabular}{lcc}
\hline \multicolumn{1}{c}{ Site } & Survivors & Non survivors \\
\hline Stomach & $6(5.4)$ & $2(1.8)$ \\
Duodenum & $34(30.4)$ & $5(4.5)$ \\
Jejunum & $7(6.3)$ & $1(0.9)$ \\
Ileum & $17(15.2)$ & $8(7.1)$ \\
Appendix & $18(16.1)$ & $2(1.8)$ \\
Large bowel & $8(7.1)$ & $1(0.9)$ \\
Gallbladder & $2(1.8)$ & $0(0)$ \\
\hline
\end{tabular}

to nearly one third of the cases, followed by ileal and appendicular perforations. One third of the patients with ileal perforation succumbed to their illness. Similarly, the site of perforation likewise did not differ significantly in survivors and non survivors (Table 3 ).

Intraoperative blood loss did not show any correration with survival. Multivariate logistic regression analysis done for the variables found to be significant from univariate analysis showed that only pulse, systolic blood pressure and creatinine were the independent variables associated with mortality. (Table 4)

\section{DISCUSSION}

Overall mortality in hollow viscus perforation in various series ranged from $10.6 \%$ to $36 \%$. $^{3-6}$ The results in the present series were comparable with most series with exception to Mulari, et al, who reported mortality of $36 \% .^{4}$ The reason for high mortality rate in Mulari series may be inclusion of only ICU patients.

As with present study, many other studies have found correlation between increasing age and mortality in perforation peritonitis. ${ }^{2,78}$ Increasing age seems to be an important prognostic factor that may probably be mediated indirectly through latent or more severe co-morbidity, poor nutritional status, general fragilty, and changed immune function. ${ }^{9}$ Because of the fact that increasing age relates to high mortality, it has been given a high score in both the scoring systems.

Similarly, male preponderance in perforation peritonitis was also comparable with other series. ${ }^{5,7}$ Higher proportion of male smokers which is a risk factor for peptic ulcer perforation maybe the reason for higher rate of perforation. Traumatic perforations resulting from physical assaults are also seen more in the male population. Several studies showed duration of symptoms to be a predictor of mortality. ${ }^{5,7}$ Delay in presentation has been attributed to many factors. Low
Table 4. Independent variables found to be significantly associated with mortality from multivariate analysis

\begin{tabular}{lccc}
\hline Variable & Coefficient & p value & $\begin{array}{c}\text { Odds } \\
\text { Ratio (OR) }\end{array}$ \\
\hline Pulse & 0.043 & 0.057 & 1.044 \\
SBP & -0.078 & 0.006 & 0.925 \\
Creatinine & 0.011 & 0.049 & 1.011 \\
& & & \\
\hline
\end{tabular}

socioeconomic status, level of literacy and long distance needed for travel to reach a referral centre are the important factors causing delay in presentation. Svanes et $\mathrm{al}^{10}{ }^{10}$ reported that delay in presentation more than 24 hours increased the mortality rate by seven to eight fold. However, in the present study, duration of symptoms did not differ significantly between survivors and non survivors.

There is a three-fold increased risk of mortality when patients are in shock on admission and the mortality approaches $50 \%$ in presence of septic shock. ${ }^{11}$ Present study showed significant association between hypotension and increased mortality in perforation peritonitis similar to other studies. ${ }^{2,78}$ Regardless of the cause, hypotension leads to diminished tissue perfusion and increased incidence of dehiscence at the repair site.

Laboratory parameters such as hemoglobin, sodium and potassium did not differ between survivors and non- survivors which correlates with published series., ${ }^{72}$ WBC count was not associated with mortality in the study by Horiuchi, et al. ${ }^{12}$ In the present series, though WBC count was a significant factor associated with mortality, multivariate analysis failed to establish it as an independent risk factor. Levels of urea and creatinine depicting the renal function had a strong association with mortality in our study as well as several other studies. , $^{2,8}$

Proximal site of bowel perforation was seen in a studies from South Asia.5,8 Duodenal ulcer perforation was the commonest site in the current study. Smoking, especially among young males, has been hypothesized for higher proportion of peptic ulcer perforation. ${ }^{13}$ Distal bowel perforation has been seen to be predominant in the western countries mainly due to higher prevalance of diverticular disease. ${ }^{14}$ On the other hand, a Nigerian study has shown 58\% typhoid perforations. ${ }^{15}$ Hence, the site of perforation has been shown to vary in different geographical regions. Overall, age, sex, site of perforation, preoperative shock, 
hypoglycemia, renal dysfunction and duration of symptoms have been reported as the determinants of mortality in patients with perforation peritonitis. ${ }^{7}$ However, from the present study, only pulse, blood pressure and creatinine were found to be significant factors from multivariate logistic regression analysis associated with mortality.

\section{CONCLUSION}

Approximately one fifth of the patients undergoing surgery for perforation peritonitis succumbed to their disease. Higher mortality was seen in elderly patients. Despite of male preponderance, larger proportion of females succumbed to their disease. Vital parameters like pulse and blood pressure were independent variables associated with mortality. Renal function test had a negative impact in survival.

\section{CONFLICT OF INTEREST}

None declared.

\section{REFERENCES}

1. Ramakrishnan K, Salinas RC. Peptic Ulcer disease. Am Fam Physician. 2007;1:1005-12.

2. Billing $A$, Fröhlich $D$, Schildberg FW. Prediction of outcome using the Mannheim peritonitis index in 2003 patients. Br J Surg. 1994;81:209-13

3. Marshall JC, Maier RV, Jimerz M. Source control in the management of severe sepsis and septic shock: an evidence- based review. Crit Care med 2004. $32: 5513-55$

4. Mulari K, Leppäniemi A: Severe secondary peritonitis following gastrointestinal tract perforation. Scand J Surg. 2004 ; 93 : $204-208$

5. Afridi SP, Malik F, Rahman S, Shamim S, Samo KA.
Spectrum of perforation peritonitis in Pakistan: 300 cases Eastern experience. World J Emerg Surg. $2008 ; 3: 31$

6. Kulkarni S, Naik A, Subramanian N. APACHE-II scoring system in perforative peritonitis. Am J Surg. 2007; $194: 549$ - 552

7. Singh $\mathrm{R}$, Kumar N, Bhattachraya A, Vajifdar $\mathrm{H}$. Preoperative predictors of mortality in adult patients with perforation peritonitis. Indian J Crit Care Med. 2011; $15: 157$ - 163

8. Jhobta RS, Attri AK, Kaushik R, Sharma R, Jhobta A. Spectrum of perforation peritonitis in Indiareview of 504 consecutive cases. World J Emerg Surg. $1006 ; 1: 26$

9. Suvas S. Advancing age and immune cell dysfunction: is it reversible or not? Expert Opin Biol Ther. $2008 ; 8: 657-668$

10. Svanes C, Lie RT, Svanes K, Lie SA, Soride O. Adverse effects of delayed delayed treatment for perforated peptic ulcer. Ann Surg. 1994 ; 220 :168 $-175$

11. Levy MM, Fink MP, Marshall JC, Abraham E, Angus D, Cook D, et al. 2001 SCCM/ESICM/ACCP/ATS/ SIS International Sepsis Definitions Conference. Crit Care Med. 2003; 31:1250 - 1256

12. Horiuchi A, Watanabe $Y$, Doi T, Sato K, Yukumi S, Yoshida $M$, et al: Evaluation of prognostic factors and scoring system in colonic perforation. World J Gastroeneterol. 2007 ; 13 (23): 3228 - 3231

13. Kocer B, Surmeli S, Solak C, Unal B, Bozkurt B, Yildirim $O$, et al: Factors affecting mortality and morbidity in patients with peptic ulcer perforation. J Gastroenterol Hepatol. 2007; 22 : 565 - 570

14. Malangoni MA, Inui T. Peritonitis the western experience. World J Emerg Surg. $2006 ; 1: 25$

15. Adesunkanmi A, Badmus T, Ogundoyin O. Causes and determinants of outcome of intestinal perforations in a semiurban African community. Ann Coll Surg HK. 2003 ; 7 : 116 - 123 